Gazi University
Journal of Science
$\mathrm{http} / /$ dergipark.gov.tr/gujs

\title{
Investigating the Effects of Forming Parameters on Molding Force and Springback in Deep Drawing Process of Thermoplastic Composite Laminates
}

\author{
Abdullah Onur OZDEMIR ${ }^{10}$, Mehmet SUBASI ${ }^{2 *}$, Cetin KARATAS ${ }^{3}$ \\ ${ }^{I}$ Department of Automotive Engineering, Faculty of Technology, Gazi University, Ankara, 06500, Turkey \\ ${ }^{2}$ Department of Machine and Metal Technology, Technical Sciences Vocational School of Higher Education, Gazi University, Ankara, O6374, \\ Turkey \\ ${ }^{3}$ Department of Manufacturing Engineering, Faculty of Technology, Gazi University, Ankara, 06500, Turkey
}

Highlights

-The molding force increases as the holding pressure increases in the thermoforming process.

- The molding force decreases as the specimen temperature increases in the thermoforming process.

- Springback increases with the increase of holding pressure in the thermoforming process.

- Springback decreases with the increase of specimen temperature in the thermoforming process.

Article Info

Received: 06 July 2020

Accepted: 13 Oct 2020

\section{Keywords}

Deep drawing

Springback

Molding force

Forming

Thermoplastic composite laminate

\begin{abstract}
The automotive industry and research centers have intensified the search for innovative solutions in the field of material technologies and have recently accelerated their work on thermoplastic based composites in line with their requirements. Thermoform method is used for rapid forming of thermoplastics and composites. In this process, mold design and especially molding parameters are important for part quality. Thermoplastic composite sheets take the shape of their final form by spring back after they come out of the mold as in sheet metals. Therefore, springback is a parameter that should be taken into account in the manufacturing process and product design. In this study, preliminary research was carried out to design the forming process in thermoform mold. The experiments were done on Nakajima test setup and according to ISO 12004 standard. In the deep drawing of thermoplastic composite laminates, the effects of different holding pressure $(0.4 ; 0.6 ; 0.8 \mathrm{MPa})$, punch speed $(90,120,150 \mathrm{~mm} / \mathrm{min})$, specimen temperature $(129$, $\left.159,169^{\circ} \mathrm{C}\right)$ and piece depth $(20,25,30 \mathrm{~mm})$ parameters on the molding force were examined and the spring back amount of deep drawn specimens was determined. As a result of the experiments, as the specimen temperature increased the molding force decreased. The molding force increased as the holding pressure increased. Increasing punch speed caused an increase in required molding force. As a result of the experiments, it was concluded that deep drawing can be made up to a depth of $25 \mathrm{~mm}$.
\end{abstract}

\section{INTRODUCTION}

Composites are the new generation materials which are going to substitute for wood, ceramic and metal used for decades. Besides their advanced mechanical qualifications in comparison with other materials, composites have a great advantage of lightness and chemical stability [1-4]. Types of fibres in composites, their weaving styles and patterns cause a difference in material qualifications [5]. Because of this composites are preferred in manufacturing parts requiring high performance. A whole range of methods has been used in forming composites which are reinforced or completely polymer. Molding by laying down manually, with prepolymerisation and thermoforming can be given as examples [6-8].

Forming composite materials with the molding method requires the least operator skills and can obtain high quality [6]. Alcock et al. were investigated the effects of drawing level, temperature and annealing 
parameters on composite material qualifications. They compared self reinforced composite laminated with the hot press to composite sheets obtained with vacuum packing. Although force variance increases at different levels during the forming process, the punch force was determined as approximately $10 \mathrm{kN}$ when the part height reaches $31 \mathrm{~mm}$ in both methods. As the pressure on the heated specimen by forming with hemispherical punch mold increases, the part thickness decreases [9]. Cabrera et al. searched forming selfreinforced polypropylene composites and glass fiber reinforced composite with a non-isothermal molding method. They determined that wrinkling in parts is related to the residual stress [10]. Lee et al. investigated random oriented glass fibre reinforced polypropylene composites formed by the molding method. They created dome-shaped specimens by heating the composite during experiments. As a result of these experiments they presented the highest and the lowest strain values caused by temperature, molding speed and glass fibre volume during the forming process [11].

That thermoplastic composites can be re-formed by heating makes it possible to molding (forming) with the thermoform method. Thermoform is a method enabling laminate to have a product in a short time. Forming thermoplastic composites as laminates provide an opportunity to manufacture composite parts in a shorter span of time. In the thermoform method, the laminate is first heated and then it is formed with a matched mold [12]. In this case, the most suitable molding force has to be known according to the blankholder force, punch speed, specimen temperature and drawing level parameters of thermoplastic composite laminates which are aimed to be used instead of sheet metals in the automotive industry. It is also important to determine the springback level enabling us to foresee the deformation after the forming process.

In this study, parameters which have an effect on molding force during forming thermoplastic composite laminates in thermoform were searched and springback behaviors of deep drawn materials were investigated. Bidirectional woven glass fiber reinforced $3 \mathrm{~mm}$ polypropylene composite materials were used in the experiments.

\section{MATERIAL METHOD}

Thermoplastic composites produced with a compression molding technique were obtained as ready to use materials. Composite material whose laminate thickness is $3 \mathrm{~mm}$ consists of $60 \%$ continuous glass fibre having $(0 / 90)_{6}$ layers and polypropylene matrix. The tensile strength of the material is $820 \mathrm{MPa}$.

Specimens were cut in a diameter of $90 \mathrm{~mm}$ via water jet. Depending on the Nakajima standard drawing level of $(\mathrm{D} / \mathrm{d}=2)$ in forming sheet metals, hemispherical punch diameter was determined as $45 \mathrm{~mm}$ [13]. After the specimens were prepared, their limits were confirmed in preliminary tests. The experimental design shown in Table 1 was implemented.

Table 1. Experimental design

\begin{tabular}{cccc}
\hline $\begin{array}{c}\text { Specimen preheat temperature } \\
\left({ }^{\circ} \mathbf{C}\right)\end{array}$ & $\begin{array}{c}\text { Punch speed } \\
(\mathbf{m m} / \mathbf{m i n})\end{array}$ & $\begin{array}{c}\text { Holding pressure } \\
(\mathbf{M P a})\end{array}$ & $\begin{array}{c}\text { Drawing depth } \\
(\mathbf{m m})\end{array}$ \\
\hline 129 (Recrystallization temperature) & 90 & 0.4 & 20 \\
159 (Heat deflection/softening & 120 & 0.6 & 25 \\
$\begin{array}{c}\text { temperature) } \\
169 \text { (Melting temperature) }\end{array}$ & 150 & 0.8 & 30 \\
\hline
\end{tabular}

The test machine used in the experiments and the way of the experiment is shown in Figure 1 schematically. Specimens were preheated according to the temperatures stated in the experimental design before they were placed between the mold and the holder. After the holding pressure adjusted in the control panel automatically by the device ( $\pm 0.05 \mathrm{MPa})$, the punch movement was started and the experiment was ended when it has reached the set-point depth. Meanwhile, the force applied in order to form the specimen and displacement change was recorded as $( \pm 0.05 \mathrm{kN})$ and $( \pm 0.05 \mathrm{~mm})$ respectively. After the punch force was 
removed, the distance was measured instantaneously. When the distance was stabilized, the height was recorded. The other experiment was conducted by removing the formed specimen out of its place.
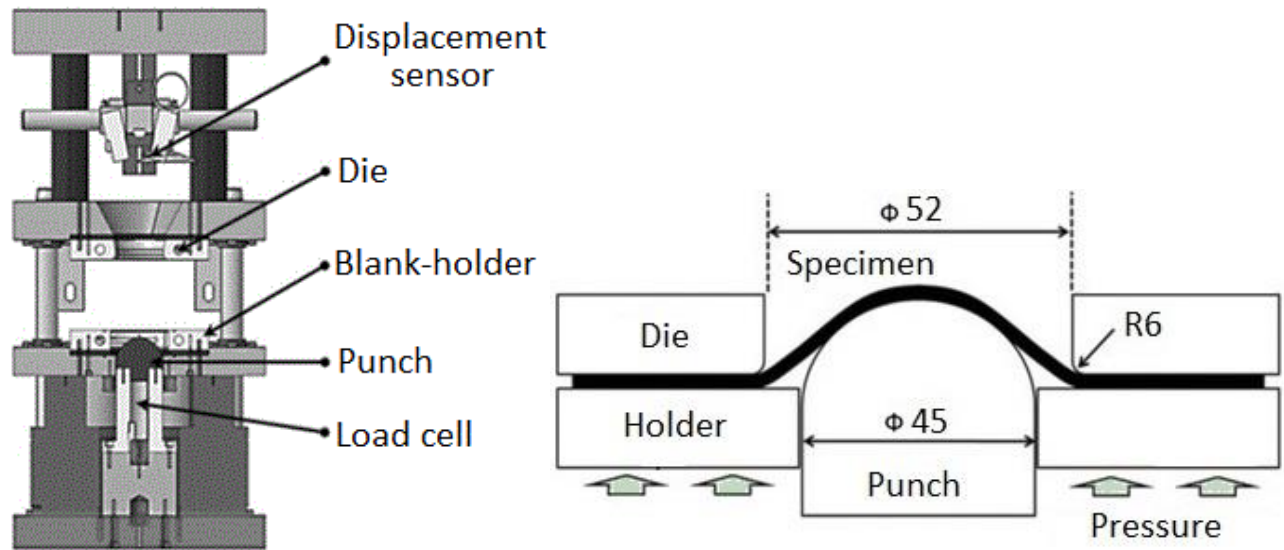

Figure 1. Nakajima test setup and schematic representation $[13,14]$

Specimens are heated with a temperature and time compensated oven. A heating clamp was placed into the mold and the forming process occurred at $55^{\circ} \mathrm{C}$ stable mold temperature defined during preliminary tests. After the punch was released, the specimen was left in the mold for a while and the height change was monitored by the displacement sensor. Also, the amount of spring-back in the specimens was verified by measuring with a digital caliper $( \pm 0.01)$ depending on the height of the specimen.

\section{THE RESEARCH FINDINGS AND DISCUSSION}

In this study, deep drawing experiments of thermoplastic composite laminates were conducted. In the experiments, blank-holder force, punch speed, specimen temperature and drawing level were changed and their effects on the molding force were examined. Diagrams were generated by taking into consideration the most suitable parameters after the experiments. Moreover, the springback behaviors in the specimen after the forming process were compared. The constant varieties in the comparisons about springbacks were shown on the diagrams. Deep drawn composite laminates were shown in Figure 2.

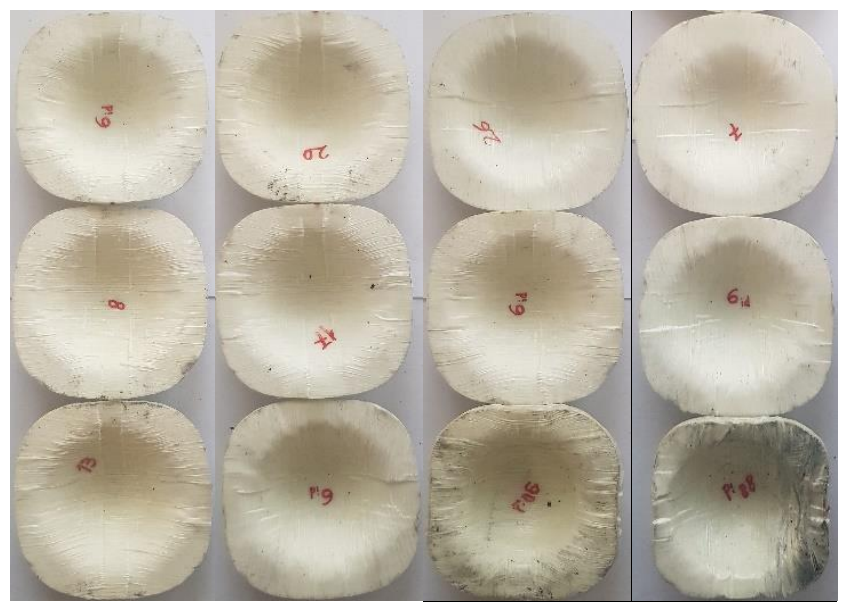

Figure 2. Specimens status after experiment

In the experiments carried out at $159{ }^{\circ} \mathrm{C}$ specimen temperature, the effect of depth change on the molding force in reference to holding pressure was shown in Figure 3. As the aimed part depth increases, the force 
value also increases and the effect of pressure has become more clear. Doubling the holding pressure for $30 \mathrm{~mm}$ was caused a $48 \%$ increase in force value. In order to prevent wrinkling and delamination, the specimen was compressed between the mold and the holder. The increase in molding force is neutral because of the increase in compression pressure.

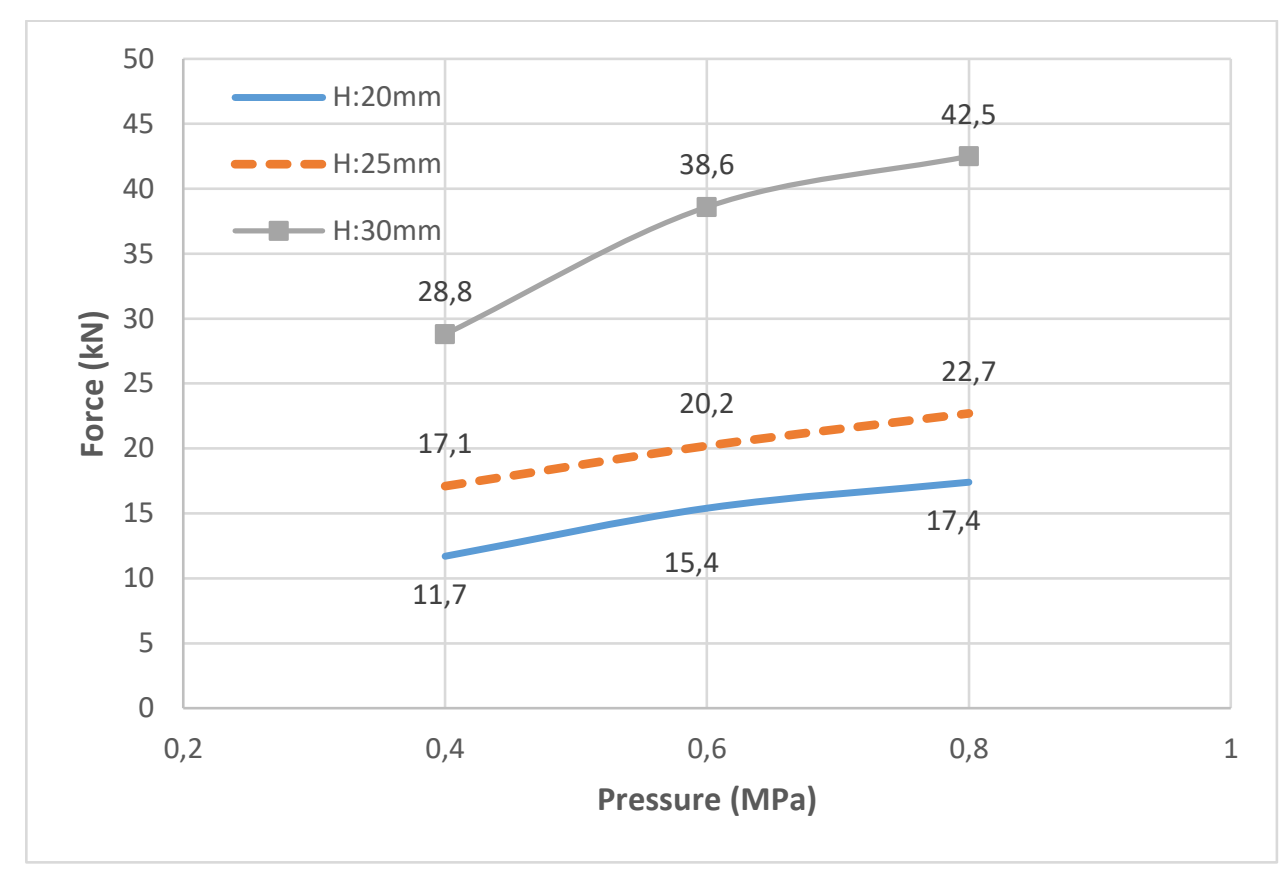

Figure 3. The effect on molding force of change of drawing depth depending on the holding pressure

In the experiments carried out at $159{ }^{\circ} \mathrm{C}$ specimen temperature, the effect of the holding pressure on molding force in reference to depth was shown in Figure 4. The molding force in the deep drawing process was increased with the increase in the holding pressure during the forming process because the matrix was compressed less by allowing the part to slide. When the pressure is $0.8 \mathrm{MPa}$, it has seen that the force needs to be increased approximately three times in order to increase depth from $20 \mathrm{~mm}$ to $30 \mathrm{~mm}$. The tension that occurred in the material related to punch geometry is not uniform and so the force curve has changed parabolically. Morrow et al. confirmed similar findings in their study about deep drawing specimens having different geometry [6]. 


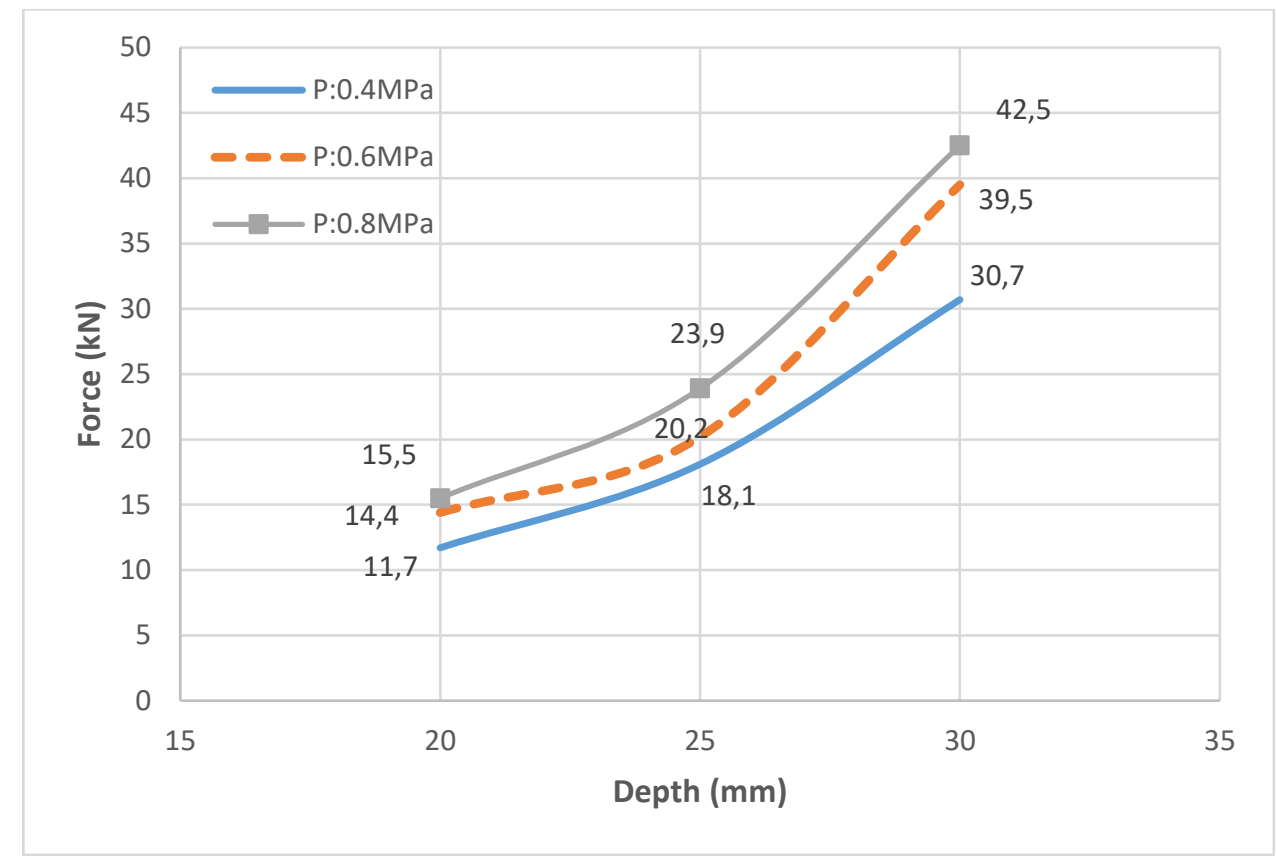

Figure 4. The effect on molding force of change of holding pressure depending on drawing depth

In the experiments done with 0.4 MPa holding pressure, the effect of different punch speeds on the molding force in reference to depth was shown in Figure 5. As the punch speed has increased, the molding force has increased with a similar tendency at three depth levels. In order to increase the drawing speed from 90 $\mathrm{mm} / \mathrm{min}$ to $150 \mathrm{~mm} / \mathrm{min}$ at $30 \mathrm{~mm}$ drawing depth, $32 \%$ more drawing force was required. Increasing punch speed was seen as a solution in order to shorten the process time and provide homogeneous specimen temperature but, molding force has increased also. When the part was drawn $30 \mathrm{~mm}$ depth at $90 \mathrm{~mm} / \mathrm{min}$ punch speed, the required molding force has increased $38 \%$ with the increase in the holding pressure from $0.4 \mathrm{MPa}$ to $0.8 \mathrm{MPa}$.

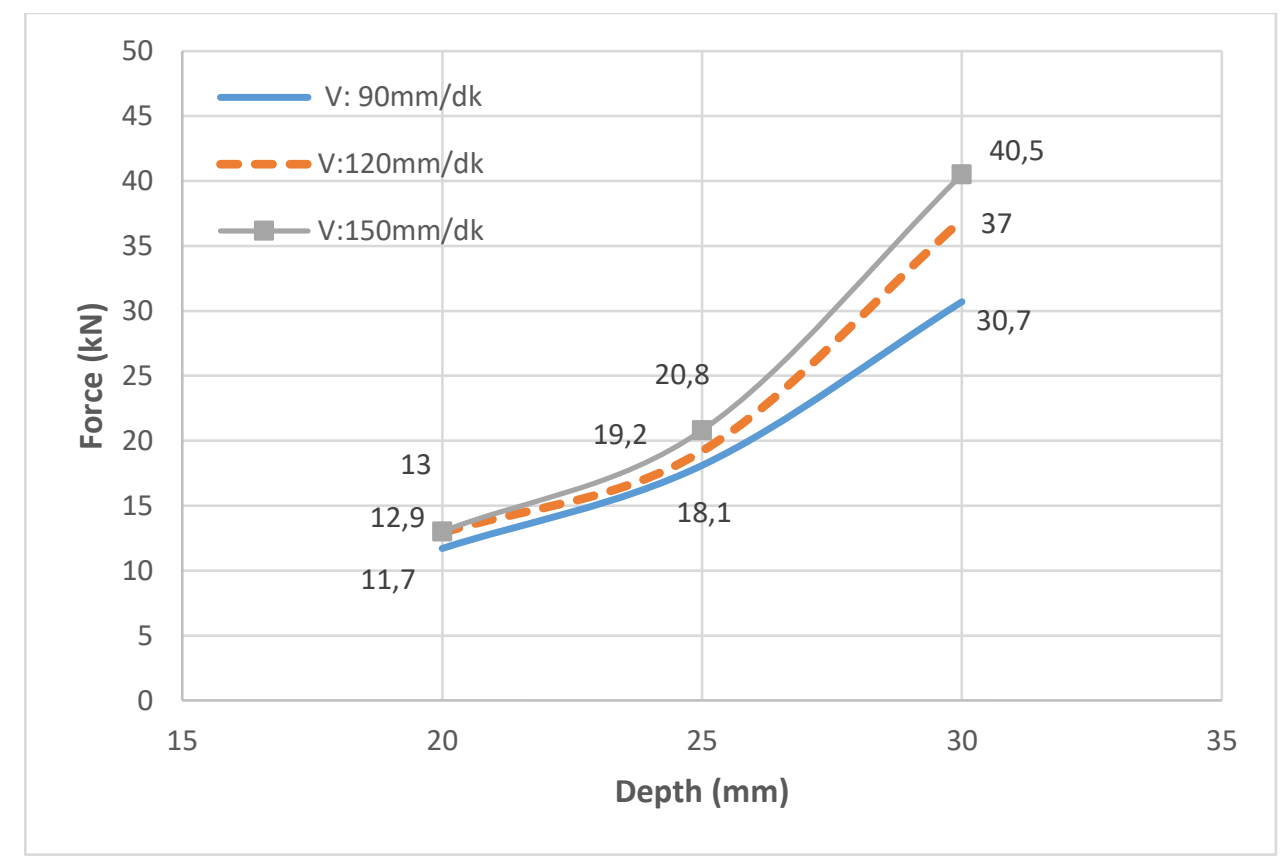

Figure 5. Molding forces according to different punch speeds depending on drawing depth 
In the experiments done with 0.4 MPa holding pressure, the effect of different specimen temperature on molding force in reference to deep drawing depth was shown in Figure 6. It was confirmed that the required molding force is higher at crystallization temperature $\left(129^{\circ} \mathrm{C}\right)$. As it was closed to the melting temperature $\left(169^{\circ} \mathrm{C}\right)$, deep drawing at a lower force can be carried out but, material quality was destroyed because of the deformation on its surface. The molding force wasdecreased by $20 \%$ with the increase in specimen temperature from $129^{\circ} \mathrm{C}$ to $159{ }^{\circ} \mathrm{C}$ at $30 \mathrm{~mm}$ depth. Since the force increase heavily depends on the fibre, even at the melting temperature the molding force was increased as the depth increases. Alcock et al. have similar results in their studies and they reported that higher forces are required for a faster molding process [9]. Because the radius of the hemispherical punch is $22.5 \mathrm{~mm}$, the specimen has started to flow cylindrically after this depth. As it can be seen in the figure, the increased level was increased after 22.5 $\mathrm{mm}$.

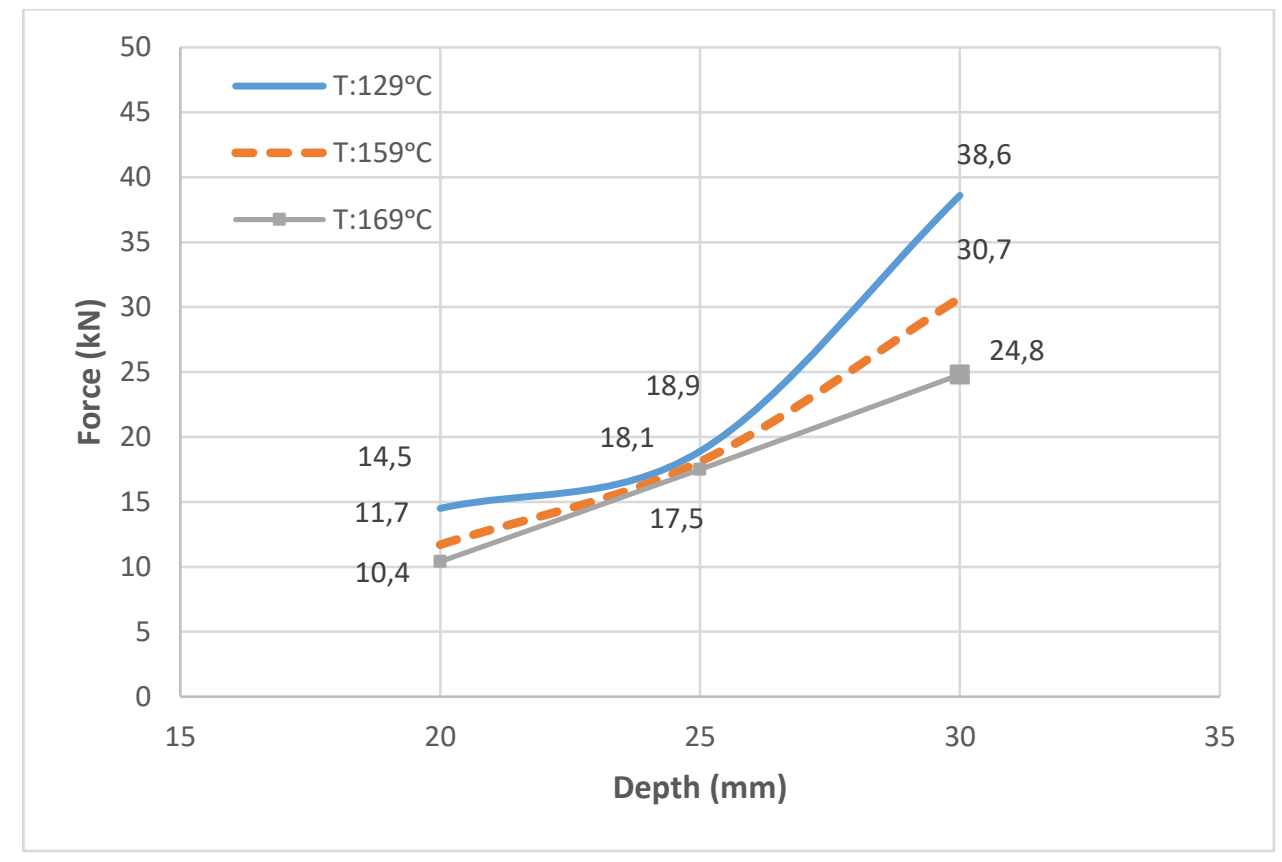

Figure 6. Molding forces according to different specimen temperatures depending on drawing depth

The forming process was completed after the punch has reached the targeted depth. After the punch was stopped, push and down forces disappeared and springback has occurred on the hemispherical part. In the preliminary tests, it was seen that the cold mold causes springback more. It is because of the cold mold decreases the specimen temperature dramatically. In this study, it was aimed to decrease the springback and the experiments were conducted at $55{ }^{\circ} \mathrm{C}$ mold temperature.

The springback cases of deep drawn specimens in reference to depth levels were shown in Figure 7 depending on (a) the blank-holder force, (b) the punch speed and (c) the specimen temperature. When the blank-holder force is $0.4 \mathrm{MPa}$, the specimen drawn to $30 \mathrm{~mm}$ depth has shrunk to $26 \mathrm{~mm}$ after the experiment. When the holding pressure is more than $0.4 \mathrm{MPa}$, the springback was $1 \mathrm{~mm}$ at every depth level. Low holding pressure has allowed the specimen to flow into the mold and the specimen is under the influence of reaction tension less. Thus, the specimen has shrunk less. 


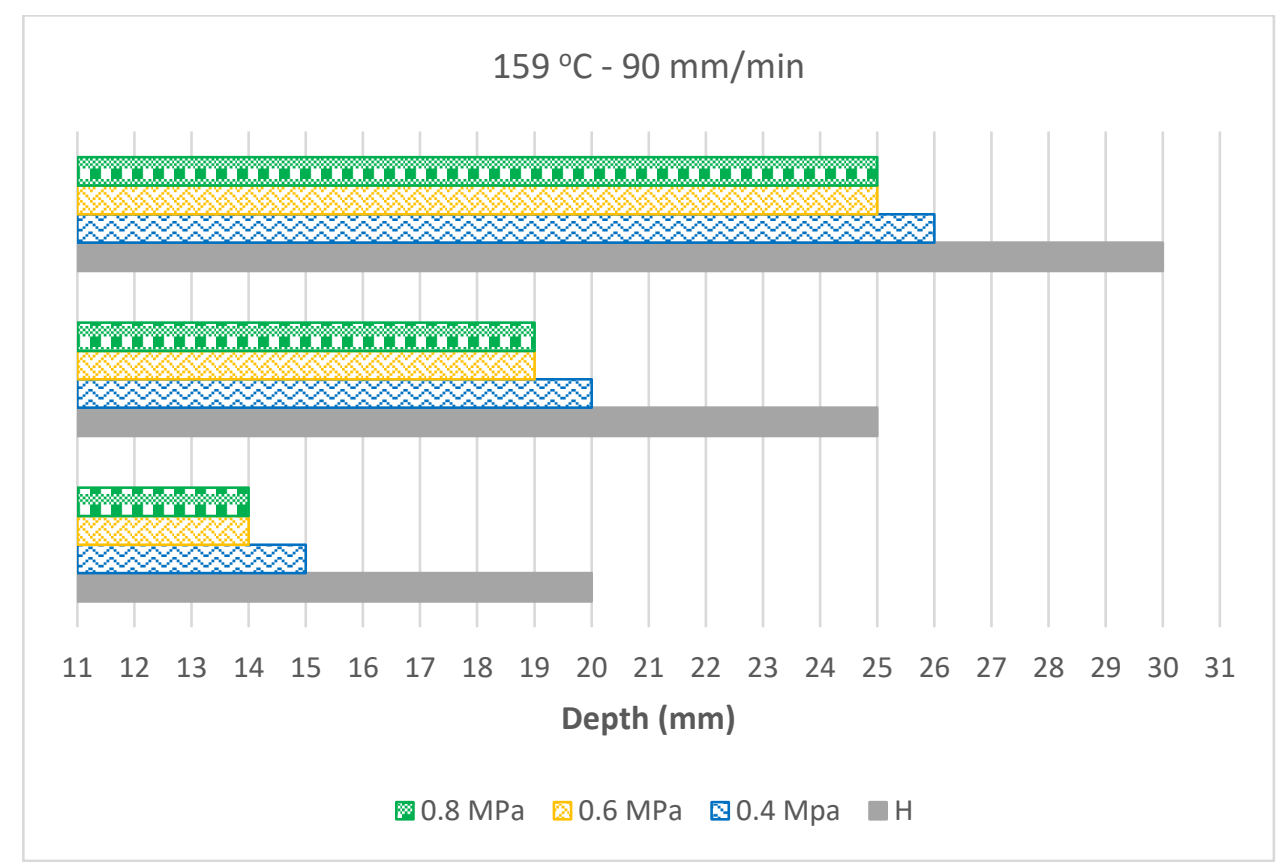

Figure 7-a. Specimen final heights depending on different holding pressure

After the specimen was drawn to $20 \mathrm{~mm}$, its depth shrunk to $18 \mathrm{~mm}$ when the punch speed is $150 \mathrm{~mm} / \mathrm{min}$. Slow punch speed increased the time for forming process and depending on this, the specimen temperature decreased. When the punch speed is high, less residual stress was observed because the specimen temperature is preserved more. In this way, high punch speed has a positive effect on springbacks.

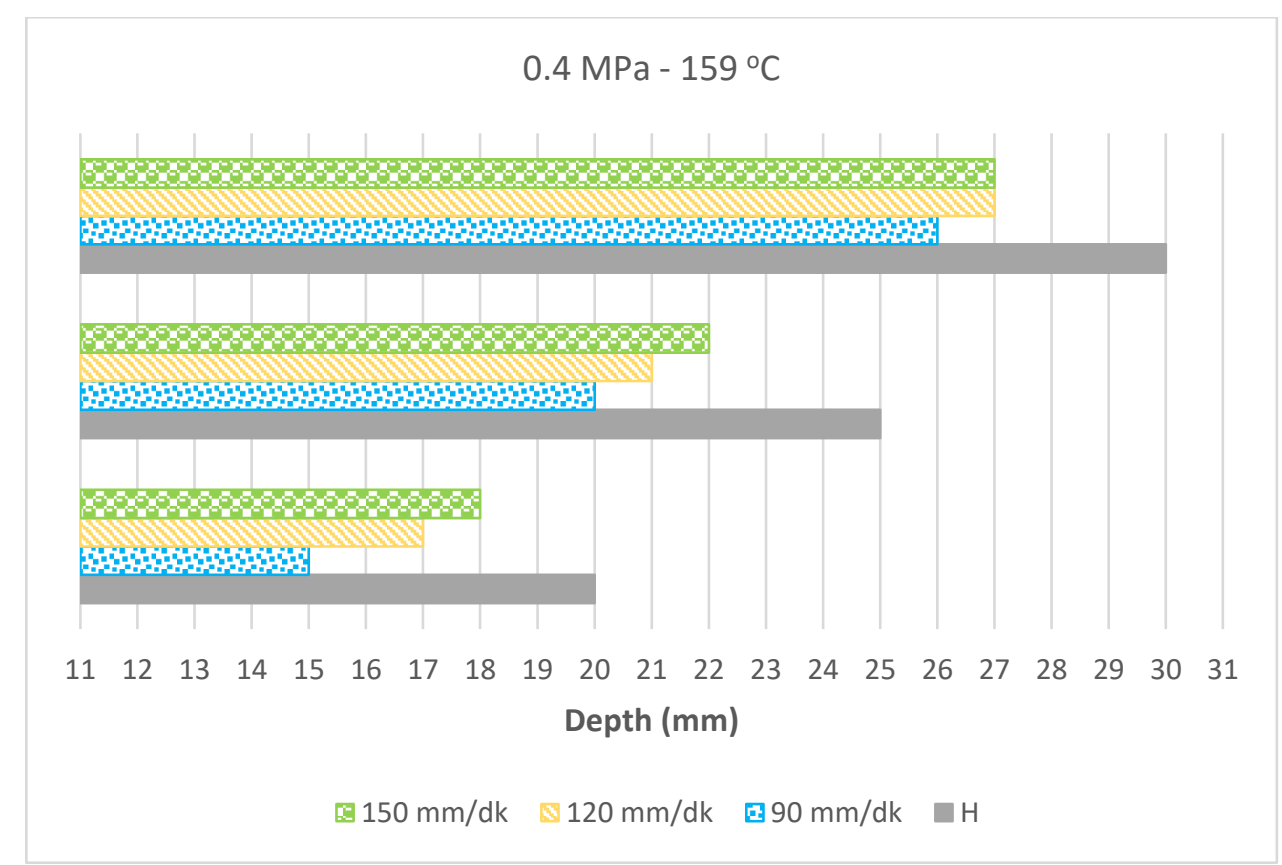

Figure 7-b. Specimen final heights depending on different punch speed

The part drawn to $25 \mathrm{~mm}$ when the specimen temperature is $159^{\circ} \mathrm{C}$ shrunk to $21 \mathrm{~mm}$ after the procedure. The most springback occurred when the specimen is drawn at crystallization temperature. As the temperature increased, the residual stress also increased and the springback decreased. When the depth is 
less, elastic deformation is also less because the punch contacts with a narrower area on the specimen surface. Therefore, the springback increased.

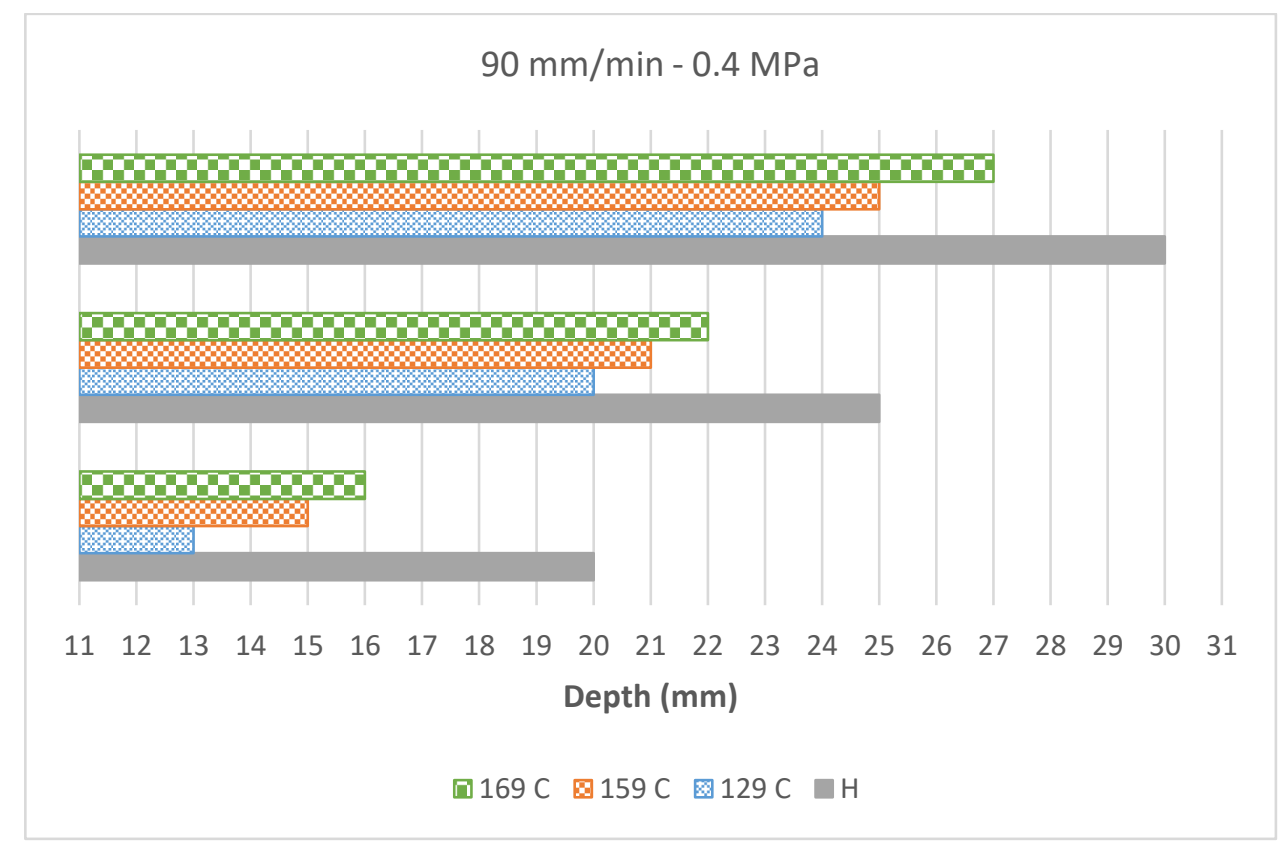

Figure 7-c. Specimen final heights depending on different specimen temperature

Generally, as the deep drawing level increases, the level of springback decreases because of the plastic deformation increases. The values about the specimen heights after the experiments were given in Table 2 .

Table 2. Specimen final heights

\begin{tabular}{|c|c|c|c|c|c|c|c|c|c|}
\hline \multirow{2}{*}{$\begin{array}{c}\text { Depth } \\
(\mathbf{m m})\end{array}$} & \multicolumn{4}{|c|}{ Holding pressure (MPa) } & \multicolumn{3}{|c|}{ Punch speed (mm/min) } & \multicolumn{3}{|c|}{ Specimen temperature $\left({ }^{\circ} \mathbf{C}\right)$} \\
\hline $\mathbf{2 0}$ & 15 & 14 & 14 & 15 & 17 & 18 & 13 & 15 & 16 \\
\hline $\mathbf{2 5}$ & 20 & 19 & 19 & 20 & 21 & 22 & 20 & 21 & 22 \\
\hline $\mathbf{3 0}$ & 26 & 25 & 25 & 26 & 27 & 27 & 24 & 25 & 27 \\
\hline
\end{tabular}

\section{RESULTS}

In the present study, polypropylene composite materials whose laminate thickness are $3 \mathrm{~mm}$ and consist of $60 \%$ continuous glass fibre laid up $(0 / 90)_{6}$ were used. The specimens used in the experiments were prepared to cut as $90 \mathrm{~mm}$ diameter by use of water jet. Thermoplastic composite laminates were preheated after the experimental setup is set, and then experiments were conducted with a deep drawing process. Three different parameters were used for the holding pressure $(0.4 ; 0.6 ; 0.8)$, for punch speed $(90,120,150$ $\mathrm{mm} / \mathrm{min})$, for the specimen temperature $\left(129,159,169^{\circ} \mathrm{C}\right)$ and for deep drawing level $(20,25,30 \mathrm{~mm})$. The effects of these parameters on molding force and springback were investigated.

As the specimen temperature increased, the molding force also decreased. However, defects occurred on the surface and structural integrity of the material because the matrix can't hold the fibre firmly enough. The required molding force increased at the crystallization temperature because the material is more brittle 
at that level. The springback level decreased as the specimen temperature increased. Thus, softening temperature $\left(159^{\circ} \mathrm{C}\right)$ was determined as the most suitable temperature for the forming process.

The molding force increased as the holding pressure increased. Increasing holding pressure caused springback. 0.4 MPa holding pressure was determined as enough for the deep drawing process carried out at softening temperature.

Increasing punch speed caused an increase in the required molding force. However, increasing the punch force increased the springback level. Meanwhile, the part quality decreased in the deep drawing process at high speeds. Therefore, it was determined that the most suitable punch speed should be $90 \mathrm{~mm} / \mathrm{min}$.

It was determined that the depth change affects the applied molding force. The springback level decreased as the deep drawing level increased. It was concluded that the deep drawing process can be done securely at the utmost $25 \mathrm{~mm}$ depth level because of the effect of punch radius in related to drawing level.

\section{ACKNOWLEDGEMENTS}

We would like to thank "Durfom İzo. ve Amb. San. Tic. A.Ş." for the supply of composite sheet materials used in this study and TÜBİTAK (The Scientific and Technological Research Council of Turkey) which supported this work within the scope of the project with code 218M194.

\section{CONFLICTS OF INTEREST}

No conflict of interest was declared by the authors.

\section{REFERENCES}

[1] Kim, D.W., Kim, Y.S., Jung, YC, Kim, S.Y., Song, J.M., Kim, M., and Kim, J., "Development of a continuous manufacturing process for self-reinforced composites using multi-step highly drawn polypropylene tapes". Polymer, 191: 122267, (2020).

[2] Lu, K., "The future of metals", Science, 328(5976): 319-320, (2010).

[3] Yan, L., Chouw, N., Jayaraman, K., "Flax Fibre and its composites - A review", Composites Part B: Engineering, 56: 296-317, (2014).

[4] Yao, S.-S., Jin, F.-L., Rhee, K.Y., Hui, D., Park, S.-J., "Recent Advances in carbon-fiberreinforced thermoplastic composites: A review", Composites Part B: Engineering, 142: 241-250, (2018).

[5] Conte, R., Ambrogio, G., Pulice, D., Gagliardi, F., Filice, L., "Incremental sheet forming of a composite made of thermoplastic matrix and glass-fiber reinforcement", Procedia Engineering, 207: 819-824, (2017).

[6] Morrow, C., Dhar, M.S, Venkatesan, S., Kalyanasundaram, S., "Stretch forming studies on thermoplastic composite", Paper presented at the 6th Australiasian Congress on Applied Mechanics, Perth, Australia (2010).

[7] Vyas, S., Goli, E., Zhang, X., Geubelle, P.H., "Manufacturing of unidirectional glass-fiberreinforced composites via frontal polymerization: A numerical study", Composites Science and Technology, 184: 107832, (2019).

[8] Bhattacharyya, D., Bowis, M., Jayaraman, K., "Thermoforming woodfibre-polypropylene composite sheets", Composites Science and Technology, 63 (3): 353-365, (2003). 
[9] Alcock, B., Cabrera, N.O., Barkoula, N.M., Peijs, T.,"Direct forming of all-polypropylene composites products from fabrics made of co-extruded tapes". Applied Composite Materials, 16 (2): 117-134, (2009).

[10] Cabrera, N.O., Reynolds, C.T., Alcock, B., Peijs, T., 2008, "Non-isothermal stamp forming of continuous tape reinforced all-polypropylene composite sheet", Composites Part A: Applied Science and Manufacturing, 39 (9): 1455-1466, (2008).

[11] Lee, J.H., Vogel, J.H., Rhee, K.Y., "An Analysis of Stretch Forming of Thermoplastic Composites", Polymer Composites, 23 (3): 442-453, (2002).

[12] Labeas, G.N., Watiti, V.B., Katsiropoulos, C.V., 2008, "Thermomechanical Simulation of Infrared Heating Diaphragm Forming Process for Thermoplastic Parts", Journal of Thermoplastic Composite Materials, 21(4): 353-370, (2008).

[13] The British Standards Institution, Metallic materials. Sheet and strip. Determination of forminglimit curves. BS EN ISO 12004 (2020).

[14] Panich, S. Liewald, M., and Uthaisangsuk, V.,"Stress and strain based fracture forming limit curves for advanced high strength steel sheet", International Journal of Material Forming, 11, pp. 643-661, (2018). 